\title{
El museo y su entorno
}

En tiempos recientes el concepto de museo no solamente ha sido cuestionado, sino también ha venido cambiando, de ser una institución ensimismada, cerrada, a una más dinámica y colaboradora con otras instituciones dedicadas a la educación y la divulgación de valores de cambio en la sociedad moderna (llámense escuelas, institutos, universidades o ministerios de educación pública).

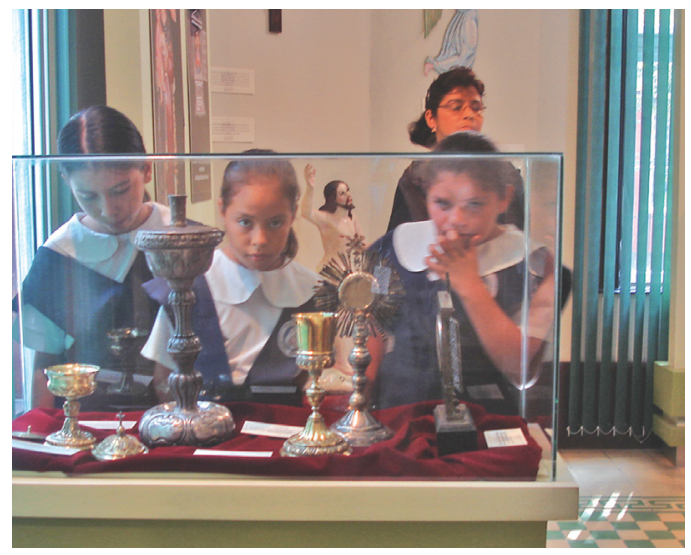

Sala temporal, MUA

Desde hace unos cien años se trata de definir al museo, ya no como un templo sagrado al que se tiene que entrar haciendo una genuflexión, y casi persignándose, para acceder a todo ese conocimiento del que solo una elite ilustrada, y con suficiente recurso económico para coleccionar, tuvo acceso en los inicios de aquella entidad como tal. ${ }^{1}$ Conforme el tiempo pasa el concepto de museo evoluciona. En la medida en que las ciencias se abrieron paso, los museos fueron especializándose; y así encontramos, a principios del siglo $\mathrm{XX}$, museos con temáticas sobre arte, culturas populares y arqueología, los dedicados a esta última ciencia vistos casi como almacenes de antigüiedades. Muchas de estas instituciones de carácter histórico se formaron con colecciones privadas y también por medio de excavaciones auspiciadas por universidades norteamericanas y europeas. Es preciso señalar que las potencias económicas de principios de siglo XX (EE. UU., Francia y Alemania, entre otros) obtienen por medio del expolio diversos bienes culturales de pueblos descendientes de

1 León, Aurora, El museo, teoría y praxis. Ediciones Cátedra, Madrid, España, 1990. p. 48. 
las antiguas civilizaciones, que dejaron este importante patrimonio cultural; y así las potencias nutrieron los fondos de gran cantidad de museos que hoy el mundo admira (el Museo del Louvre, el Museo del Vaticano, y un largo etcétera), con el pretexto de conservar este patrimonio que, en caso de quedar en manos de esos países expoliados, se perdería debido a los escasos recursos, la falta de personal adiestrado y la "ignorancia" generalizada del pueblo. Napoleón expolió a Egipto de una gran parte de su patrimonio cultural e histórico; Howard Carter envió una cantidad importante de bienes culturales a Inglaterra y - por qué no decirlo - mucho de nuestro patrimonio cultural cerámico arqueológico fue a parar a los fondos del Museo de Las Américas, en España. Esta tendencia todavía existe aún en varios museos, como el recientemente inaugurado Quai Branly, el museo de las culturas en Francia.

Sin embargo, estos países fueron los primeros en cuestionar el concepto tradicional de museo, y comienzan a darle rumbos más didácticos a las exposiciones y discursos museográficos, así como a extender la promoción cultural hasta el punto de crear la que hoy es una de las más rentables industrias en el mundo: el turismo cultural. Gracias a esta industria aprendemos lo que ellos designan como arte y cultura, y lo que no lo es. Nos ubicamos dentro del panorama mundial de la cultura como pueblos tercermundistas, con

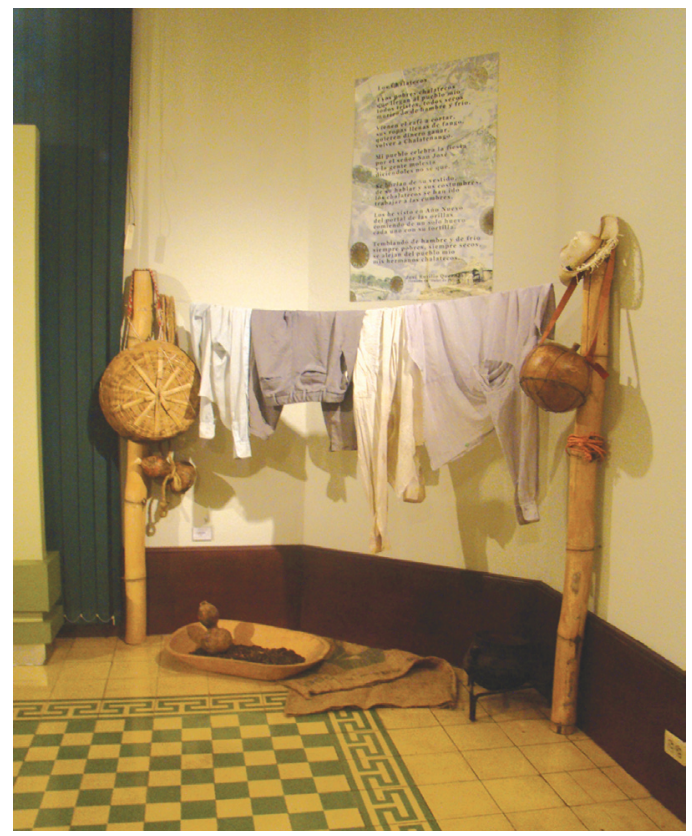

Sala Temporal, MUA una cultura "atrasada" al compararnos con sus logros estéticos; obtenemos cánones estéticos de estas instituciones primermundistas, que rigen nuestras expresiones culturales y que nos enseñan a consumir su arte, sus expresiones culturales, por ejemplo. De esta manera, la Mona Lisa - el famoso retrato de Leonardo DaVinci-, se encuentra hasta el más humilde de nuestros hogares por medio del cartel, la copia del cuadro, el documental de televisión y hasta el "papel tapiz" para la computadora bajado del sitio web de un museo o del promocional en Internet de la película "El Código Da Vinci". Triste ilusión es el pensar que so- 


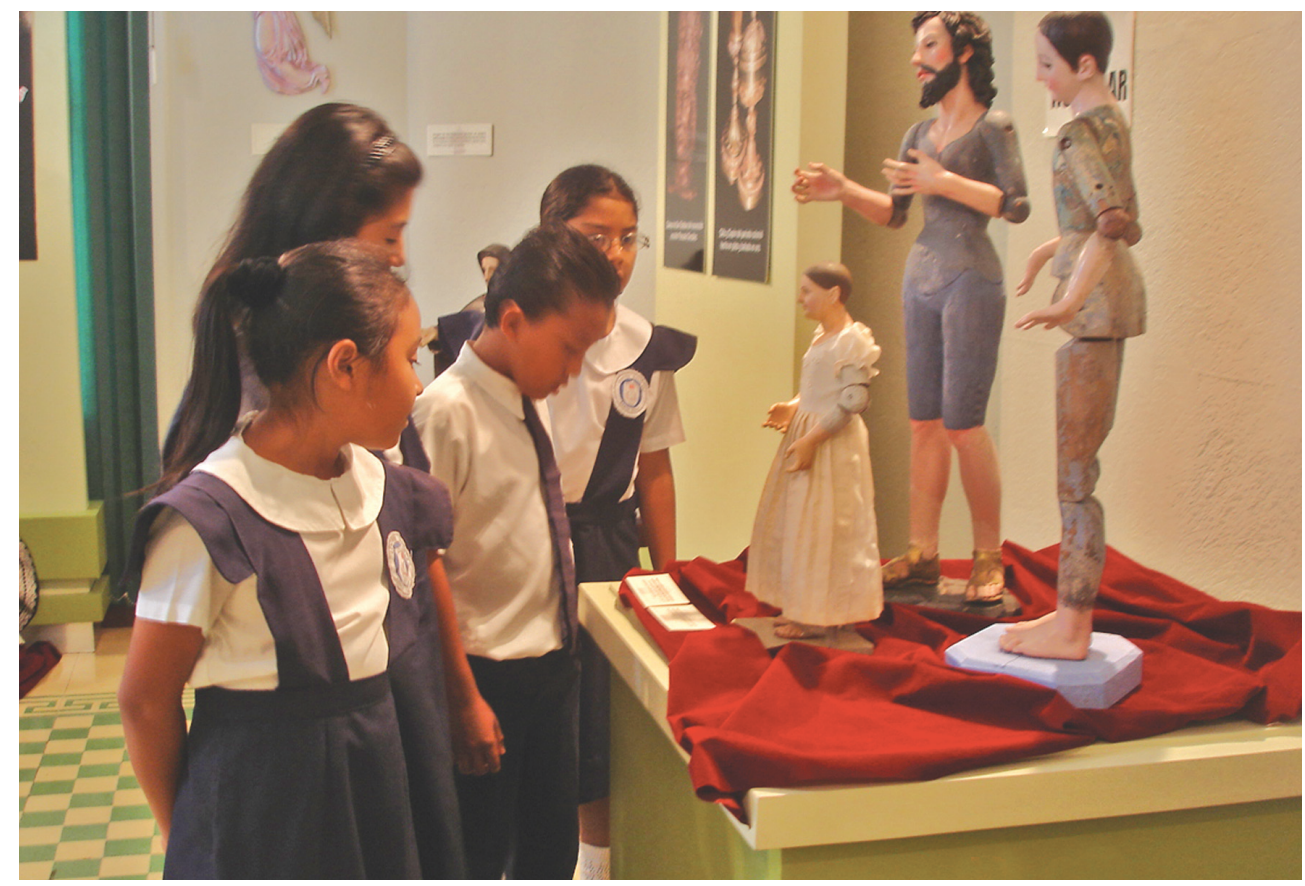

Sala Temporal, $M U A$

mos cultos o que, por lo menos, "nos estamos culturizando". Pero ¿qué pasa con nuestra cultura local y nuestros museos? Con frecuencia suelo hacerme estas preguntas: ¿por qué la mayoría de nuestros museos aburren al visitante? ¿Por qué la gente dice que basta con ir una vez al museo? ¿Qué es lo que necesitan nuestros museos; promoción, oferta, respaldo económico? Las respuestas no se pueden dar a la ligera; y creo que en especial, para ser responsables ante estos interrogantes, debemos estudiar con más ahínco el fenómeno de los museos en nuestro país, su historia, sus aciertos y desaciertos; medirlos en cuanto a los logros alcanzados. Aunque esto supone ir más allá de comparar los datos estadísticos de visitantes, puesto que no solamente por ser el más visitado un museo se convierte en el mejor o en el más grande. Tampoco es el activismo cultural lo que nos llevará a alcanzar esa utopía tan perseguida de ser un museo ideal. ¿No será que nos hemos puesto a crear museos sin haber reflexionado de qué modo podemos incidir en la sociedad por medio de estos como entes ideológicos, para orientar la cultura salvadoreña hacia valores mas humanos y prácticos? ¿Qué ofrecen nuestros museos?, ¿conocimiento aislado?, ¿pura información sin que el espectador o visitante pueda conectarla con la realidad? Y unas preguntas más: ¿Los museos salvadoreños tienen contacto con su realidad y con la comunidad que les rodea? ¿Cuál es la incidencia 
que el museo tiene en su entorno inmediato y mediato? ¿Está dotado de instrumentos que le propicien esa buscada interactividad con el entorno?

Si se habla de que el museo no solamente debe conservar una colección determinada, sino también en su entorno; es decir, una zona o una localidad. Entonces, la labor del museo debe de ser la de conservación del patrimonio local. Pero ¿cuál es ese patrimonio por conservar? ¿Es solamente el patrimonio arquitectónico? ¿Qué pasa con el patrimonio humano, social, con sus anécdotas, elucubraciones, preocupaciones cotidianas?... ¿De qué manera un museo inserto en un sector con mucha afluencia humana, con problemas sociales y económicos, puede tanto reflejar como contribuir al desarrollo de esa zona? ¿Qué valores debemos de fomentar en la comunidad para hacer del lugar uno que sea ejemplar o, por lo menos, más tranquilo y atractivo para el visitante extranjero? Las exposiciones actuales no solo deben de tener un grado de academicismo o desarrollo de contenidos científicos, sino también han de estar dirigidas en sus temáticas a la gente que habita el entorno del museo. ${ }^{2}$ Es necesario definir y delimitar el patrimonio tangible e intangible que el mu-

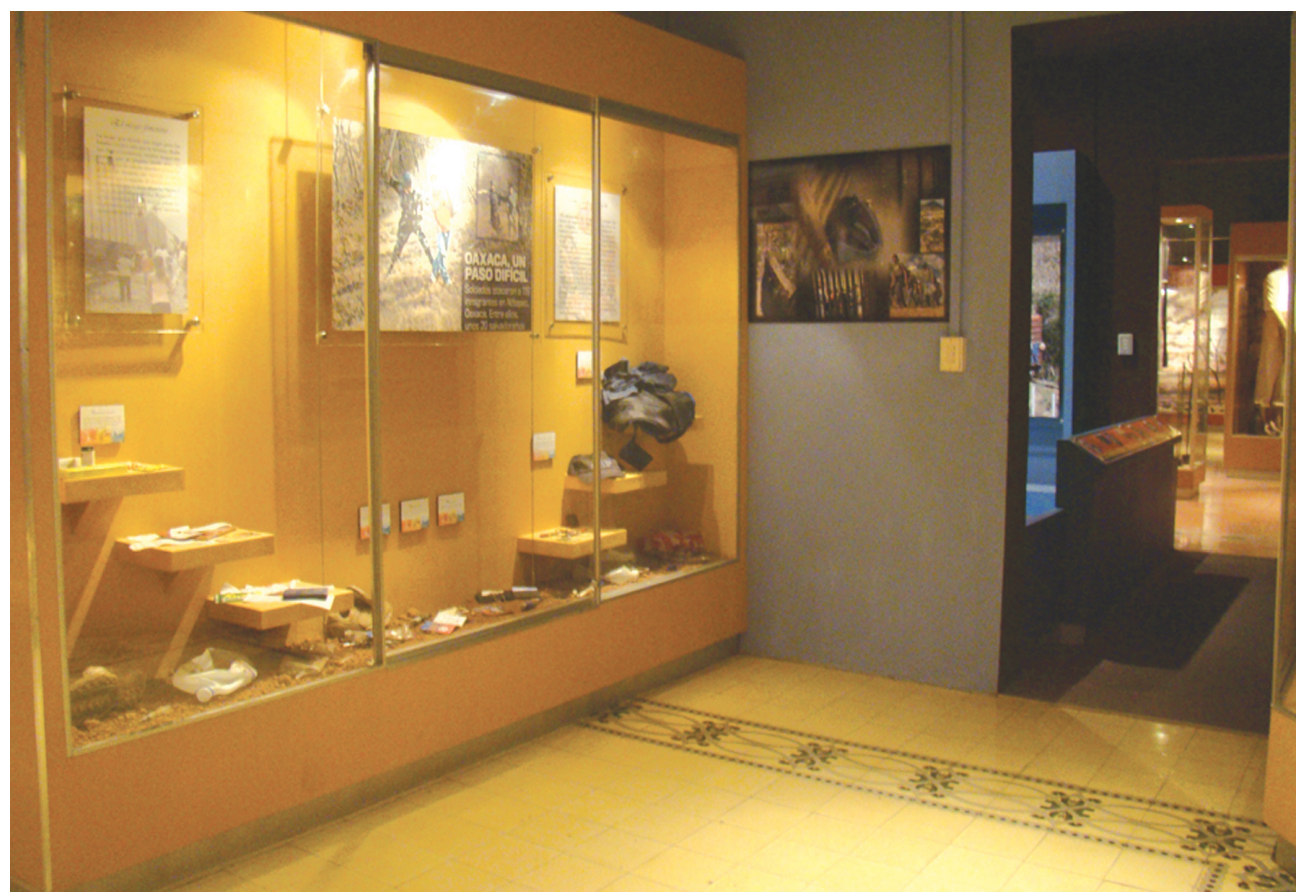

Sala "Las migraciones”, MUA

2 Yunen, Emilio, "La nueva museología", www.cielonaranja.com/rey_museografia.htm 
seo puede investigar, conservar y difundir. ¿Hacia qué personas o entidades debemos avocarnos para que nos ayuden en esta compleja y titánica tarea? Sin duda, unas de las respuestas se encuentran en la gente misma, en la población de la zona, de la comunidad, en las diversas entidades que componen el hábitat del museo, el ir y venir incesante del estudiante y del transeúnte y hasta en la gastronomía urbana, la cultura local de la zona.

El museo está llamado a plasmar todos aquellos fenómenos sociales que han determinado, y los que continúan determinando, el devenir de nuestra historia; y no deben de exponer solamente los discursos oficialistas de los gobiernos de turno y reflejar solo aquel conocimiento académico que muchas veces termina aislado, tanto por la deficiencia del guión como por la poca visión de su director, así como del equipo multidisciplinario que apoye la construcción del discurso museográfico a través de estos guiones. Muchos de los sectores sociales que se encuentran en la base de nuestra pirámide social no tienen acceso a un museo, y no tienen el mas mínimo interés en entrar o saber qué es un museo porque no se ven reflejados en los discursos museográficos. Todo ese lumpenproletariado también puede y debe tener la oportunidad de contar sus desgarradoras historias, que no siempre son del agrado de todos por no tener el debido ingrediente esteticista o "de clase", por no ser letrados. Todas estas personas e identidades tienen algo que ver en el desarrollo de la cultura; y si el museo no estudia los fenómenos de esta "ecología urbana" llega a ser solamente una isla llena de "antigüedades o tesoros culturales", dentro de un océano de entes vivos ignorantes e ignorados. Los sectores sociales generan cultura por sí mismos, y ya es hora de que sean tomados en cuenta aunque sea por un museo. Si los diversos sectores que componen la sociedad no se ven reflejados en el museo, su contenido no logrará superar aquella vieja percepción del museo como "templo sagrado" dentro del cual no se hace más.

Con el surgimiento de las nuevas ciencias sociales (antropología, sociología, historia, etc.) en El Salvador, los museos están recurriendo a nuevos campos de investigación social en donde pueden renovar sus discursos museográficos, brindando nuevas temáticas de exposiciones más llamativas para la población, y ya no ofreciéndoles exposiciones científicamente estériles en donde solo se encuentran las piezas y el conocimiento sin dar o abrir un senda con la realidad. De esa manera, el museo se divorcia de la realidad y el público o colectivo de visitantes no se encuentra reflejado, desligándose del museo sin extraer un conocimiento que contribuya a su realidad.

El nuevo museo buscará entender a la obra patrimonial o artística y cultural ya 
no como un objeto aislado con categoría o rango hipostático en sí mismo, sino como un producto que es parte de un colectivo donde puede observar tanto el devenir histórico como la idiosincrasia y realidad que vive ese colectivo. ${ }^{3}$ Pero si los esquemas de un museo deben ser abiertos, ¿hasta donde llega el alcance de la apertura de estos esquemas sin tener que abusar del concepto de museo? En la medida en que las investigaciones sean serias, la institución museística tendrá la capacidad de definir los puntos de real interés para las ciencias sociales, estéticas, histórica; y, además, encontramos aquí que tendrá ya no solamente interés en el tipo de colección, sino en los investigadores que la estudian y los estrategas que planifican su difusión, dotando de información contextual a las colecciones, formando un criterio selectivo que defina las piezas de las colecciones como objetos vivos y no como meros bienes culturales, y como producción material que refleje la actividad y laboriosidad del pueblo salvadoreño, así como su problemática diaria.

El museo está llamado a plasmar fenómenos sociales y culturales que afectan históricamente nuestra cultura, y tiene que difundir el estudio de estos hechos para establecer paradigmas que ayuden al pueblo a tener una visión más clara o consciente de cómo estos fenómenos moledan nuestra identidad cultural.

\section{Referentes bibliográficos}

García Canclini, Nestor, Culturas híbridas, Ediciones Grijalbo, México, 1990.

León, Aurora, El museo, teoría y praxis, Ediciones Cátedra, Madrid, 1990.

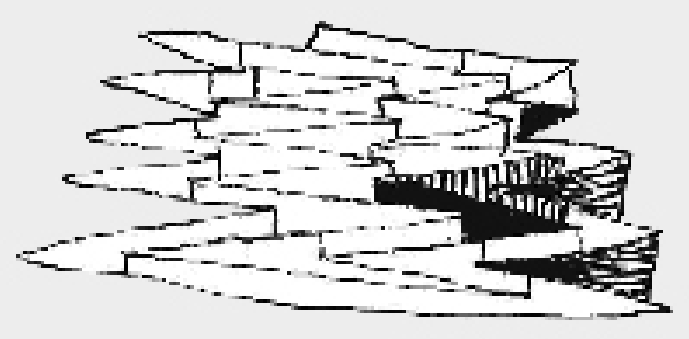

3 “A favor del conocimiento científico Los nuevos museos Jorge Wagensberg”. e-spacio.uned.es/fez/ eserv.php?pid 